ОСОБЕННОСТИ АККУМУЛЯЦИИ ТЯЖЕЛЫХ МЕТАЛЛОВ В ЛАНДШАФТАХ СУРА-СВИЯЖСКОГО МЕЖДУРЕЧЬЯ ПРИВОЛЖСКОЙ ВОЗВЫШЕННОСТИ

\author{
Кузнецова О.Г. \\ Научный руководитель - д.г.-м.н., профессор Лаврусевич А.А. \\ (Национальный исследовательский Московский государственный строительный \\ университет, Москва, 129337, Ярославское шоссе, 26.)
}

\begin{abstract}
Аннотация. Приведены данные исследования концентраций некоторых металлов $(\mathrm{Cd}, \mathrm{Cr}$, $\mathrm{Cu}, \mathrm{Fe}, \mathrm{Mn}, \mathrm{Pb}, \mathrm{Zn})$ на территории Сура-Свияжского междуречья Приволжской возвышенности. На исследуемой территории происходят процессы аккумуляции железа и меди. Максимальные концентрации зарегистрированы в иллювиальном горизонте ГПЗ «Присурский»- 884 мг/кг. Железо является типоморфным элементом для исследованной территории. Помимо процессов аккумуляции, железо поступает из материнских пород. Также значительны концентрации меди - до 2,39 мг/кг, зарегистрированные вблизи города Алатырь.
\end{abstract}

Ключевые слова: тяжелые металлы, железо, Сура-Свияжске междуречье Приволжской возвышенности, железо как типоморфный элемент.

\title{
FEATURES OF ACCUMULATION OF HEAVY METALS IN LANDSCAPES SURA - SVIAZHSKY WATERSHED PRIVOLZHSKY HILLS
}

\begin{abstract}
Kuznetsova O.G.
Scientific adviser - Doctor of Geology and Mineralogy Sciences, Professor Lavrusevich A.A. (Moscow State University of Civil Engineering, 26, Yaroslavskoye Sh., 129337, Moscow, Russia)

Abstract. The data of the study of the concentrations of some metals $(\mathrm{Cd}, \mathrm{Cr}, \mathrm{Cu}, \mathrm{Fe}, \mathrm{Mn}, \mathrm{Pb}$, $\mathrm{Zn}$ ) on the territory of the Sura-Sviyazhsky interfluve of the Volga Upland are presented. In the study area, the processes of accumulation of iron and copper are taking place. The maximum concentrations were registered in the illuvial horizon of the Prisursky GPP - $884 \mathrm{mg} / \mathrm{kg}$. Iron is a typomorphic element for the studied area. In addition to accumulation processes, iron comes from parent rocks. Copper concentrations are also significant - up to $2.39 \mathrm{mg} / \mathrm{kg}$, registered near the city of Alatyr.
\end{abstract}

Keywords: Heavy metals, iron, Sura-Sviyazhsk interfluve of the Volga Upland, iron as a typomorphic element. 


\section{ВВЕДЕНИЕ}

Исследования проводились на территории Сура-Свияжского междуречья Приволжской возвышенности (рис.1). Отбирались пробы почв и воды. В качестве среды для почвенной вытяжки использовалась 1н $\mathrm{HCl}$. Кислая среда раствора позволяет экстрагировать кислоторастворимые формы металлов: ионы металлов в виде обменных катионов, сорбированные формы минеральным и органическим веществом почвы. В условиях техногенного загрязнения кислая среда переводит в раствор оксиды и сульфиды тяжелых металлов, последние являются основными компонентами техногенных выбросов.

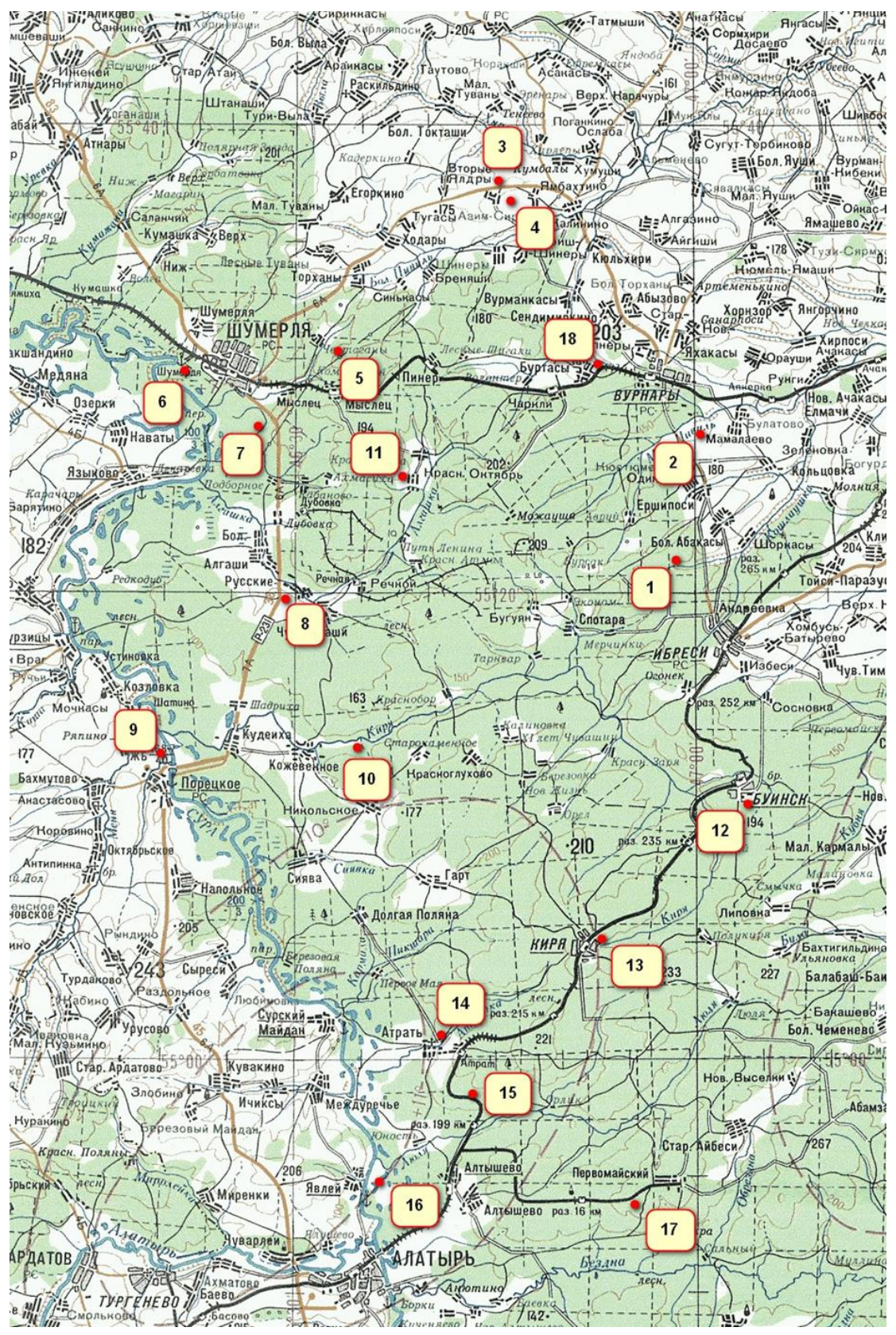

Рисунок 1. Физико-географическая карта района исследования с обозначенной областью исследования (номерами отмечены места ключевых участков). 


\section{МЕТОДОЛОГИЧЕСКИЕ ОСНОВЫ}

Аналитические исследования велись с помощью атомно-эмиссионного спектрометра (оптического) с индуктивно-связанной плазмой (АЭС). Метод является пригодным для большого набора химических элементов с высокой чувствительностью и широким динамическим диапазоном определяемых концентраций. Жидкая проба распыляется в поток газа аргона, проходящего через индукционную катушку, создающую высокочастотное магнитное поле. Под действием поля происходит разрушение молекул и возбуждение атомов, сопровождающееся эмиссией светового излучения. С целью выделения большого количества спектральных линий разных элементов и измерения их интенсивности используется полихроматор и полупроводниковый детектор.

\section{РЕЗУЛЬТАТЫ ИССЛЕДОВАНИЯ И ИХ ОБСУЖДЕНИЕ}

В точке №6 (см.табл.№1), пойма реки Сура, у города Шумерля, в верхнем органогенном горизонте концентрации железа достигала 450 мг/кг.

Таблица 1. Концентрации некоторых металлов на исследуемой территории СураСвияжского междуречья Приволжской возвышенности.

\begin{tabular}{|c|c|c|c|c|c|c|c|c|}
\hline № & Место взятия образца & $\mathrm{Cd}$ & $\mathrm{Cr}$ & $\mathrm{Cu}$ & $\mathrm{Fe}$ & $\mathrm{Mn}$ & $\mathrm{Pb}$ & $\mathrm{Zn}$ \\
\hline 1 & $\begin{array}{l}\text { Точка 1. Горизонт } \mathrm{A}_{1} \\
\text { Ельник-зеленомошник }\end{array}$ & 0,046 & 0,001 & 21,0 & 51,5 & 10,7 & 0,25 & 0,82 \\
\hline 2 & Горизонт $\mathrm{A}_{2}$ & 0,0023 & 0,001 & 0,46 & 45,0 & 9,45 & 0,20 & 0,39 \\
\hline 3 & Горизонт В & 0,0001 & 0,001 & 0,65 & 13,9 & 2,68 & 0,13 & 0,82 \\
\hline 4 & Горизонт С & 0,010 & 0,102 & 0,59 & 96,5 & 4,30 & 0,087 & 0,39 \\
\hline 5 & $\begin{array}{l}\text { Точка 2. Горизонт } \mathrm{A}_{1} \\
\text { Смешанный лес }\end{array}$ & 0,039 & 0,153 & 0,90 & 479 & 22,8 & 0,42 & 1,69 \\
\hline 6 & Горизонт $\mathrm{A}_{2}$ & 0,035 & 0,001 & 1,00 & 120 & 2,82 & 0,25 & 0,61 \\
\hline 7 & Горизонт ВС & 0,0001 & 0,001 & 1,05 & 175 & 3,45 & 0,30 & 2,59 \\
\hline 8 & $\begin{array}{l}\text { Точка 3. Горизонт В. } \\
\text { Пахотное поле. Люцерна. }\end{array}$ & 0,014 & 0,272 & 1,69 & 159 & 6,15 & 0,35 & 1,16 \\
\hline 9 & $\begin{array}{l}\text { Горизонт С. Дерново- } \\
\text { слабоподзолистая. }\end{array}$ & 0,017 & 0,166 & 1,11 & 121 & 2,11 & 0,18 & 1,15 \\
\hline 10 & $\begin{array}{l}\text { Точка 4. Горизонт } \mathrm{A}_{1}-\mathrm{A}_{2} . \\
\text { Поле. Разнотравье. }\end{array}$ & 0,0001 & 0,172 & 0,56 & 457 & 10,1 & 0,34 & 0,33 \\
\hline 11 & Горизонт В & 0,031 & 0,001 & 1,41 & 150 & 7,53 & 0,35 & 1,63 \\
\hline 12 & Горизонт ВС & 0,016 & 0,147 & 1,08 & 118 & 4,45 & 0,31 & 1,63 \\
\hline 13 & $\begin{array}{llll}\text { Точка } & 5 . & \text { Горизонт } & \mathrm{A}_{1} .\end{array}$ & 0,0001 & 0,001 & 1,03 & 80,9 & 27,2 & 0,94 & 1,00 \\
\hline
\end{tabular}




\begin{tabular}{|c|c|c|c|c|c|c|c|c|}
\hline & $\begin{array}{l}\text { с.Чертоганы. } \\
\text { Широколиственный } \\
\text { ЛЭП. Выруб.к. }\end{array}$ & & & & & & & \\
\hline 14 & Горизонт В & 0,0073 & 0,001 & 1,37 & 184 & 7,53 & 0,26 & 0,93 \\
\hline 15 & Горизонт ВС & 0,017 & 0,001 & 1,42 & 166 & 3,44 & 0,30 & 0,79 \\
\hline 16 & $\begin{array}{lll}\text { Точка } 6 . & \text { Горизонт } & \mathrm{A}_{1} . \\
\text { Чернозем. } & \text { Пойма } & \text { реки } \\
\text { Сура. } & & \\
\end{array}$ & 0,057 & 0,086 & 2,12 & 450 & 21,2 & 0,76 & 3,07 \\
\hline 17 & Горизонт ВС & 0,038 & $<0,001$ & 0,93 & 175 & 6,19 & 0,20 & 0,88 \\
\hline 18 & Точка 7. Горизонт $\mathrm{A}_{1}$ & 0,013 & $<0,001$ & 0,80 & 39,0 & 12,7 & 0,26 & 1,15 \\
\hline 19 & Горизонт $\mathrm{A}_{2}$ & 0,034 & $<0,001$ & 0,85 & 37,3 & 4,95 & 0,085 & 0,28 \\
\hline 20 & Горизонт C & 0,026 & $<0,001$ & 0,76 & 57,4 & 2,88 & 0,055 & 0,26 \\
\hline 21 & Точка 8. Горизонт $\mathrm{A}_{1}$ & 0,014 & $<0,001$ & 0,78 & 49,5 & 13,1 & 0,32 & 7,9 \\
\hline 22 & Горизонт $\mathrm{A}_{2}$ & 0,045 & $<0,001$ & 0,80 & 67,2 & 7,95 & 0,16 & 1,69 \\
\hline 23 & Горизонт ВС & 0,014 & $<0,001$ & 0,87 & 98,7 & 3,07 & 0,074 & 0,56 \\
\hline 24 & Точка 9 (пойма р.Сура) $\mathrm{A}_{1}$ & 0,024 & $<0,001$ & 1,29 & 167 & 6,73 & 0,28 & 0,86 \\
\hline 25 & Горизонт В & $<0,0001$ & 0,034 & 1,22 & 117 & 7,87 & 0,18 & 0,75 \\
\hline 26 & Точка 10. Горизонт $A_{1}$ & 0,033 & $<0,001$ & 1,23 & 66,7 & 5,90 & 0,17 & 0,42 \\
\hline 27 & Горизонт В & 0,001 & $<0,001$ & 0,92 & 44,1 & 1,14 & 0,046 & 2,52 \\
\hline 28 & $\begin{array}{l}\text { Точка 11. Красный октябрь. } \\
\text { Подзолистая } \quad \text { супесчаная } \\
\text { почва. Горизонт } \mathrm{A}_{1} / \mathrm{A}_{2}\end{array}$ & 0,008 & $<0,001$ & 1,10 & 61,1 & 13,3 & 0,24 & 1,18 \\
\hline 29 & Точка 12. Горизонт $\mathrm{A}_{2}$ & 0,032 & $<0,001$ & 1,12 & 22,8 & 2,52 & 0,105 & 0,47 \\
\hline 30 & Горизонт В & $<0,0001$ & $<0,001$ & 1,11 & 50,6 & 2,25 & 0,051 & 0,70 \\
\hline 31 & Горизонт ВС & 0,025 & $<0,001$ & 0.92 & 72,5 & 1,46 & 0,044 & 0,20 \\
\hline 32 & Горизонт C & $<0,0001$ & $<0,001$ & 0,88 & 24,0 & 0,76 & 0,026 & 0,26 \\
\hline 33 & Точка 13. Горизонт В & $<0,0001$ & $<0,001$ & 0,91 & 74,4 & 7,76 & 0,099 & 0,46 \\
\hline 34 & Горизонт ВС & $<0,0001$ & $<0,001$ & 0,87 & 87,3 & 5,81 & 0,088 & 0,43 \\
\hline 35 & Точка 14. Горизонт В & 0,010 & $<0,001$ & 0,72 & 884 & 3,58 & 0,35 & 0,16 \\
\hline 36 & Горизонт ВС & 0,001 & $<0,001$ & 0,95 & 162 & 0,24 & 0,068 & 0,27 \\
\hline 37 & Точка 15. Горизонт $\mathrm{A}_{2} / \mathrm{B}$ & 0,005 & 0,212 & 0,82 & 584 & 14,8 & 0,424 & 1,45 \\
\hline 38 & Горизонт C & 0,001 & 0,328 & 0,67 & 275 & 5,44 & 0,19 & 0,72 \\
\hline 39 & $\begin{array}{l}\text { Точка 16. Горизонт } \mathrm{A}_{1} . \\
\text { Сура. Затон. Разнотравье }\end{array}$ & 0,017 & 0,237 & 1,99 & 535 & 15,0 & 0,59 & 2,46 \\
\hline 40 & Горизонт ВС & 0,029 & 0,279 & 2,33 & 573 & 16,1 & 0,54 & 2,26 \\
\hline 41 & Горизонт C & 0,014 & 0,099 & 1,71 & 545 & 10,2 & 0,53 & 2,79 \\
\hline 42 & Точка 17. Горизонт $\mathrm{A}_{1} / \mathrm{A}_{2}$. & 0,011 & 0,133 & 0,16 & 32,3 & 0,93 & 0,12 & 0,14 \\
\hline
\end{tabular}




\begin{tabular}{|l|l|l|l|l|l|l|l|l|}
\hline & Сосны. Ягель. & & & & & & & \\
\hline 43 & Горизонт ВС & 0,035 & 0,203 & 0,24 & 21,4 & 0,64 & 0,031 & 0,10 \\
\hline 44 & $\begin{array}{l}\text { Точка 18. Горизонт А } \\
\text { «Август». Затон. }\end{array}$ & 0,035 & 0,372 & 2,00 & 235 & 34,7 & 0,90 & 1,80 \\
\hline 45 & Горизонт В & $-0,003$ & 0,305 & 1,37 & 300 & 18,3 & 0,48 & 1,41 \\
\hline 46 & Горизонт ВС. Ил. & 0,014 & 0,292 & 1,20 & 316 & 19,3 & 0,65 & 3,09 \\
\hline 47 & $\begin{array}{l}\text { Вода. Сура - Порецкое } \\
48\end{array}$ & 0,003 & 0,300 & 0,069 & 0,57 & 0,10 & 0,009 & 0,029 \\
\hline 49 & $\begin{array}{l}\text { Вода. Сура - Алатырь } \\
\text { Пруд. }\end{array}$ & $<0,0001$ & 0,224 & $<0,001$ & 0,22 & 0,03 & $<0,001$ & 0,029 \\
\hline
\end{tabular}

Железо для данной территории является типоморфным элементом. Также значительны концентрации меди - 2,12 мг/кг. Однако, данный показатель не превышал ПДК (3 мг/кг). Точки № 5,7,11 также находились в округе города Шумерля. По мере приближения к городу концентрации железа увеличиваются с 39 мг/кг в точке №7 до 80 мг/кг в точке №5. Также в точке №5 повышены концентрации меди - 1,42 мг/кг. Таким образом, концентрации железа и меди увеличиваются по мере приближения к городу.

Вблизи города Вурнары в точках №2 и 18 концентрации железа также значительны: 479 мг/кг в точке №2, находящейся непосредственно у сельскохозяйственных ландшафтов, до 235 мг/кг в точке №18 у города Вурнары. Значительны концентрации меди - до 2 мг/кг.

Самые северные, исследованные нами районы, относятся к точкам №3 и 4. Все показатели не превышали ПДК. Однако, концентрации железа также значительны: до 457 мг/кг в верхнем органогенном горизонте в точке №4, находящейся на луговом ландшафте.

Точка №9 находилась в пойме реки Сура, непосредственно у села Порецкое. Концентрации железа в верхнем органогенном горизонте доходили до 167 мг/кг.

В точках №13,14,15, находящихся на территории ГПЗ «Присурский», все определенные концентрации тяжелых металлов, не превышали ПДК. Концентрации железа доходили до 884 мг/кг в иллювиальном горизонте.

Точка №16 - у затона реки Сура, вблизи города Алатырь. Следует отметить аккумуляцию меди и железа на территории ГПЗ. Меди в иллювиальном горизонте - до 2,39 мг/кг, а железа - 573 мг/кг.

\section{ВЫВОДЫ}


Таким образом, на территории Сура-Свияжского междуречья Приволжской возвышенности происходят процессы аккумуляции железа и меди. Максимальные концентрации зарегистрированы в иллювиальном горизонте ГПЗ «Присурский» - 884 мг/кг. Железо является типоморфным элементом для исследованной территории. Помимо процессов аккумуляции, железо поступает из материнских пород. Также значительны концентрации меди - до 2,39 мг/кг, зарегистрированные вблизи города Алатырь.

\section{ЛИТЕРАТУРА.}

1. Кузнецова О.Г. Оценка степени трансформации ландшафтов Сура-Свияжского междуречья Приволжской возвышенности // ПОТАПОВСКИЕ ЧТЕНИЯ - 2019. Сборник материалов ежегодной Всероссийской научно-практической конференции, посвященной памяти доктора технических наук, профессора Александра Дмитриевича Потапова. Москва: Национальный исследовательский Московский государственный строительный университет, 2019. С.134-138.

2. Перельман А.И., Касимов Н.М. Геохимия ландшафта: Учебное пособие. Издание 3-е, переработанное и дополненное. Москва: Астрея-2000, 1999. 768 с. 